\title{
Stimulating Effects of $\beta$-Myrcene on Molting and Multiplication of the Pine Wood Nematode, Bursaphelenchus xylophilus
}

\author{
Yuji Hinode, Yoshihiro Shuto and Hiroyasu Watanabe* \\ Department of Agricultural Chemistry, Faculty of Agriculture, \\ Ehime University, Tarumi, Matsuyama 790, Japan
}

Received December 3, 1986

\begin{abstract}
The stimulating effects of monoterpenes in pine trees on the molting and the multiplication of the pine wood nematode were investigated. The results indicated that the molting of the dispersal 4th stage larva $\left(\mathrm{L}_{\mathrm{IV}}\right)$ to the adult nematode was stimulated by these monoterpenes, especially $\beta$ myrcene. The population of the nematode cultured on fungal mats of B. cinerea, A. kikuchiana and C. miyabeanus increased considerably in the presence of a small amount of $\beta$-myrcene. This compound seemed to play a hormone-like role for both the molting of $\mathrm{L}_{\mathrm{IV}}$ and the multiplication of the nematode.
\end{abstract}

Biological and ecological investigations concerning the pine wood nematode, Bursaphelenchus xylophilus, which causes serious damage to pine trees in Japan, have been extensive. ${ }^{1 \sim 8)}$ In the life cycle of the nematode, the dispersal 4 th stage larvae $\left(\mathrm{L}_{\mathrm{IV}} \mathrm{s}\right)$ carried by the sawyer are responsible for the infection of living pine trees. ${ }^{3,4)}$ Since the $\mathrm{L}_{\mathrm{IV}} \mathrm{S}$ are dauer, ${ }^{9)}$ which is a form specialized for survival and dispersal, they have a special morphological structure and lack the feeding function. ${ }^{3)}$ So, molting of $\mathrm{L}_{\mathrm{IV}}$ to adult is necessary to resume multiplication after transmigration to a living pine tree. It was considered that some chemical stimuli contained in pine trees would promote the molting of $\mathrm{L}_{\mathrm{IV}} \mathrm{S}$ to adult nematodes and subsequent multiplication.

Previously, we reported that volatile monoterpenes in pine trees, especially $\beta$-myrcene, attract the nematodes. ${ }^{8)}$ Furthermore, we recognized that the resistance of the tree to the nematode infection was related to the amount of $\beta$-myrcene. ${ }^{10)}$ This clear relationship might be attributed to the physiological roles of $\beta$ myrcene for the molting and/or the multiplication of the nematode, since both processes were essential for the infection as well as transmigration to the pine tree.

In this paper, we describe the stimulating effects of monoterpenes, especially $\beta$-myrcene, on the molting and the multiplication of the pine wood nematode.

\section{MATERIALS AND METHODS}

Chemicals. All chemicals used were of the highest quality commercially available.

Microorganism. The cultured nematodes and the $\mathrm{L}_{\mathrm{IV}} \mathrm{S}$ were obtained by our method. ${ }^{8)}$ The fungi, Botrytis cinerea, Alternaria kikuchiana and Cochliobolus miyabeanus, were generous gifts from the Laboratory of Plant Pathology of Ehime University.

Assay for molting of $L_{\mathrm{IV}}$. About $1,000 \mathrm{~L}_{\mathrm{IV}}$ s were put on $1 \mathrm{ml}$ of $1.5 \%$ agar in a glass vessel $(18 \mathrm{~mm}$ i.d. $\times 40 \mathrm{~mm})$. Each test sample $(3 \mu \mathrm{l})$ was absorbed on a piece of filter paper $(7 \times 15 \mathrm{~mm})$ attached to the stopper of the vessel. It was left in a dark chamber at $23^{\circ} \mathrm{C}$. After $48 \mathrm{hr}, 50$ nematodes were taken out randomly from the vessel and their structure was observed to distinguish adults from $\mathrm{L}_{\mathrm{IV}}$ s by the structural differences between stages ${ }^{3)}$ under a microscope $(\times 150)$. The results are indicated as a percentage of the molted adults.

Assay for multiplication. A fungus was cultured on a

\footnotetext{
* To whom correspondence should be addressed.
} 


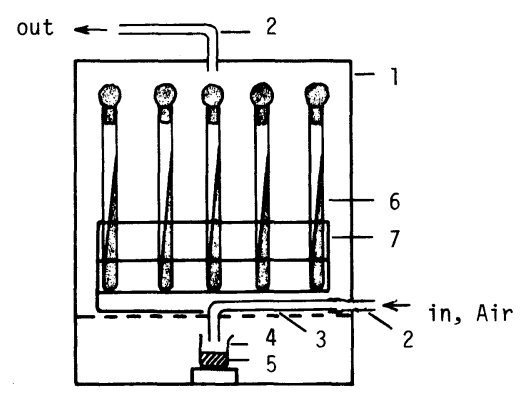

FIG. 1. Apparatus for Testing Effects of Volatile Compounds on the Growth of Pine Wood Nematodes.

1 , plastic box $(\mathrm{W} 30 \times \mathrm{L} 25 \times \mathrm{H} 35 \mathrm{~cm}) ; 2$, vinyl tube $(4 \mathrm{~mm}$ i.d.); 3 , glass tube ( $3 \mathrm{~mm}$ i.d.); 4 , beaker $(10 \mathrm{ml}) ; 5$, sample; 6 , slant; 7 , testing tube stand.

potato dextrose agar medium in testing tubes $(18 \mathrm{~mm}$ i.d. $\times 180 \mathrm{~mm}$ ) for 10 days at $20^{\circ} \mathrm{C}$. Then, about 200 nematodes were inoculated on the fungal mats of $B$. cinerea and A. kikuchiana. In the case of $C$. miyabeanus, about 400 nematodes were inoculated. The nematodes were incubated for multiplication in a rectangular plastic desiccator (1 in Fig. 1), in which a constant air stream (3.51/hr) was introduced through tubes ( 2 and 3 in Fig. 1) to vaporize a sample (5 in Fig. 1). The desiccator was left at $23^{\circ} \mathrm{C}$ with $95 \%$ humidity in a dark growth cabinet. In the case of $\beta$-myrcene, one liter of air contained about $10 \mathrm{mg}$ of the compound. To separate the nematodes from each testing tube, water was added and left at $23^{\circ} \mathrm{C}$. After $1 \mathrm{hr}$ the nematodes in the water were collected. This procedure was repeated 3 more times to collect the nematodes that had crept into agar. The number of the nematodes collected was counted under a microscope $(\times 40)$. The result was expressed as the average number of the nematodes of 5 testing tubes.

Mycelial dry weight. On the tenth day, 9 testing tubes were taken out from the desiccator used for examining the multiplication of the nematodes on $B$. cinerea. A fungal mat was harvested from each tube by boiling with water. The residual mycelium was dried at $110^{\circ} \mathrm{C}$ for $5 \mathrm{hr}$ and the hyphal weight was measured.

\section{RESULTS AND DISCUSSION}

During the developmental stages of the pine wood nematode, B. xylophilus, the dispersal 4th stage larva $\left(\mathrm{L}_{\mathrm{IV}}\right)$ participates in infection of living pine trees through the medium of the pine sawyer. ${ }^{3,4)}$ Therefore, $\mathrm{L}_{\mathrm{IV}}$ is the dauer, which is a nonfeeding form specialized for survival and dispersal. ${ }^{9)}$ When such larvae get on a living pine tree, they molt to adult
TABLE I. EFFECTS OF MONOTERPENES ON Molting of $\mathrm{L}_{\mathrm{IV}}$

\begin{tabular}{lc}
\hline Compound & $\begin{array}{c}\text { Molting rate } \\
(\%)\end{array}$ \\
\hline Control & $9.6 \pm 3.8$ \\
$\alpha$-Pinene & $21.5 \pm 9.6$ \\
$\beta$-Pinene & $13.3 \pm 10.1$ \\
3-Carene & $18.4 \pm 7.5$ \\
$\beta$-Myrcene & $40.4 \pm 5.2$ \\
l-Limonene & $23.3 \pm 14.7$ \\
Resin & \\
\end{tabular}

a The value represents the mean of 4 trials and standard deviation.

$b$ Separated from the pine tree, $P$. densiflora.

nematodes and resume multiplication. The molting of $\mathrm{L}_{\mathrm{IV}}$ to adult could be observed easily at low magnification by the differences in their morphological structures, such as differences in shapes of the head and tail and disappearence of the stylet, esophagus and esophageal gland in $\mathrm{L}_{\mathrm{IV} \cdot} \cdot{ }^{3}$ ) The effects of monoterpenes on the molting are shown in Table I. About $10 \%$ of $\mathrm{L}_{\mathrm{IV}} \mathrm{S}$ developed to adult nematodes without chemical stimulation. The molting was accelerated in the presence of $\beta$-myrcene vapor $(40.4 \%)$. Other monoterpenes also stimulated the molting, but their activity was lower than that of $\beta$ myrcene. A similar tendency was observed in the attracting test for the nematode described previously. ${ }^{8)}$ Considering the above results, it might be concluded that monoterpenes, especially $\beta$-myrcene, contained in a pine tree would be effective for the molting of $\mathrm{L}_{\mathrm{IV}} \mathrm{s}$ after transmigration from the sawyer to pine trees.

After developing to the adult stage from $\mathrm{L}_{\mathrm{IV}}$, the nematode starts to multiply rapidly under favorable circumstances. It is known that the nematode feeds on parenchymatous cells of pine wood $^{11)}$ and fungi grown in the cells. ${ }^{12)}$ Dozono $^{13)}$ examined the suitability of various kinds of fungi for the multiplication of the nematode. Three kinds of these fungi were used as the diet for the nematode to assay for the multiplication. B. cinerea was found to be the most suitable media for growth of the nematode, while $C$. miyabeanus was not. $A$. 

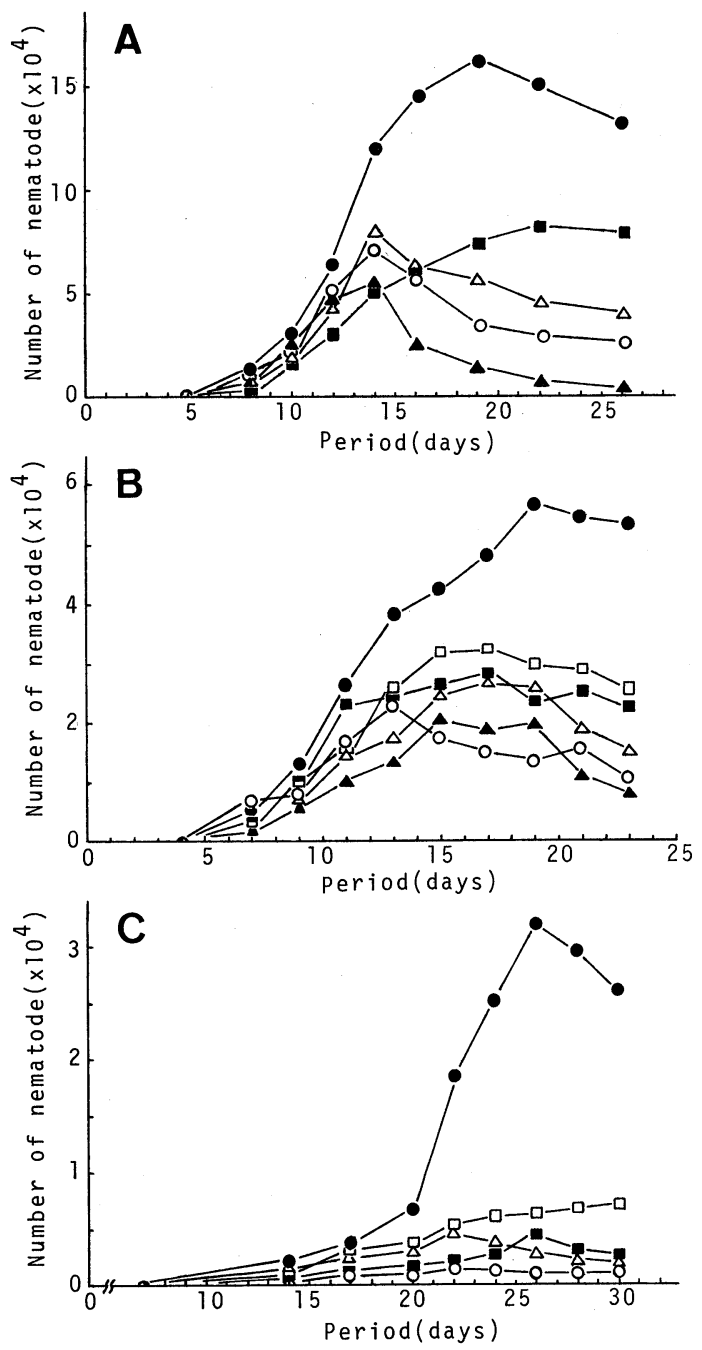

FIG. 2. Effects of Monoterpenes on the Growth of Pine Wood Nematodes on B. cinerea (A), A. kikuchiana (B) and $C$. miyabeanus $(\mathbf{C})$.

$\bigcirc$, control; $\bigcirc, \beta$-myrcene; $\triangle, \alpha$-pinene; $\square, \beta$-pinene; 3-carene; $\boldsymbol{\Delta}$, l-limonene.

kikuchiana was moderately suitable. When $B$. cinerea and $A$. kikuchiana were used with $\beta$ myrcene, the nematode could multiply rapidly showing a maximum number of about 150,000 and 60,000, respectively (A and $\mathbf{B}$ in Fig. 2). The nematode could multiply even on the medium of $C$. miyabeanus with $\beta$-myrcene and its population level reached about 30,000 per tube (C in Fig. 2). In the presence of the other monoterpenes, the multiplication did not dif-
TABLE II. EFFECTS OF MONOTERPENES ON THE GROWTH of Botrytis cinerea

\begin{tabular}{lc}
\hline Sample & $\begin{array}{c}\text { Mycelial weight } \\
(\mathrm{mg})\end{array}$ \\
\hline Control & 84.7 \\
$\alpha$-Pinene & 85.6 \\
$\beta$-Pinene & 56.7 \\
$\beta$-Myrcene & 75.9 \\
l-Limonene & 44.0 \\
3-Carene & 81.1 \\
\hline
\end{tabular}

a Mean of 9 testing tubes.

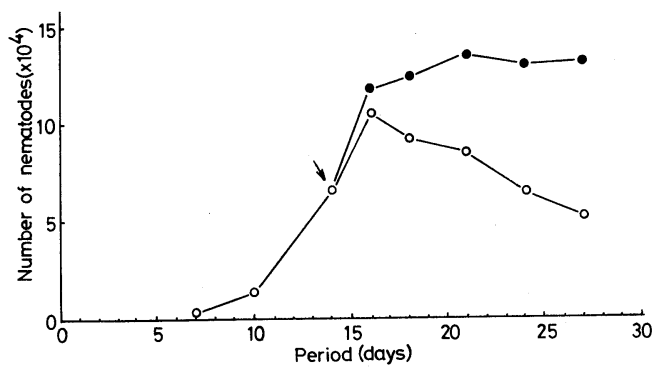

FIG. 3. Effects of $\beta$-Myrcene on Pine Wood Nematodes on $B$. cinerea.

$\bigcirc$, control; $\bigcirc, \beta$-myrcene; $\rightarrow$, start of sample supply.

fer much from the control. The multiplication was observed to be depressed a little by $l$-limonene. However, this depression might be due to growth inhibition of $B$. cinerea by $l$ limonene (Table II). While, $\beta$-myrcene did not change the hyphal weight, but increased the nematode population. After culturing for about 2 weeks on $B$. cinerea, the number of nematodes decreased gradually and many dead nematodes were observed. However, when $\beta$-myrcene vapor was supplied about 2 days before reaching the maximum population level of the nematode, the dead nematodes evidently decreased (Fig. 3). In a recent investigation, we found a growth factor in $B$. cinerea corresponding to $\beta$-myrcene in pine trees. Probably, when the dead nematodes were observed, this substance disappeared. $\beta$ Myrcene may replace this substance as a growth factor. From these results, $\beta$-myrcene was expected to play a hormone-like role in the growth of the nematode. 
Considering the attracting activity ${ }^{8)}$ and the present hormone-like activity of $\beta$-myrcene, a small difference of $\beta$-myrcene content in pine trees might affect the resistance or susceptibility of the tree when infected by the nematode. Details of the resistance to the nematode, $B$. xylophilus, depending on $\beta$-myrcene content will be described elsewhere.

Acknowledgments. The authors are grateful to Professor N. Ishibashi and Dr. E. Kondo, Saga University, for their kind advice and valuable discussion. This work was supported in part by a Grant-in-Aid for Scientific Research from the Ministry of Education, Science and Culture of Japan and a grant from the Toyota Foundation.

\section{REFERENCES}

1) Y. Mamiya, Rev. Plant Protec. Res., 5, 46 (1972).
2) Y. Mamiya, Jpn. J. Nematol., 5, 16 (1975).

3) Y. Mamiya and N. Enda, Nematologica, 18, 159 (1972).

4) K. Morimoto and A. Iwasaki, J. Jpn. For. Soc., 54, 177 (1972).

5) M. Miyazaki, K. Oda and A. Yamaguchi, J. Jpn. Wood Res., 23, 255 (1977).

6) N. Ishibashi and E. Kondo, Appl. Ent. Zool., 12, 293 (1977).

7) M. Miyazaki, A. Yamaguchi and K. Oda, J. Jpn. For. Soc., 60, 203 (1978).

8) M. Ishikawa, Y. Shuto and H. Watanabe, Agric. Biol. Chem., 50, 1863 (1986).

9) N. Ishibashi and E. Kondo, Jpn. J. Nematol., 4, 1 (1974).

10) H. Watanabe, Kagaku to Seibutsu, 20, 123 (1982).

11) Y. Mamiya and T. Kiyohara, Nematologica, 18, 120 (1972).

12) T. Kobayashi, Forest Pests, 24, 199 (1975).

13) Y. Dozono, Bull. Kyushu Branch Jpn. For. Soc., 27, 210 (1974). 